\title{
The Public distress domain of Quality of Life correlates directly and independently with BMI in pre-operative morbidly obese patients awaiting metabolic surgery
}

\author{
Aftab, SAS; Reddy, N; Piya, MK; Fraser, I; Menon, V; \\ Bridgwater, S; Halder, L; Kendrick, D; Kumar, S; Barber, TM \\ University Hospitals Coventry and Warwickshire, Warwick Medical School
}

\section{Background}

Metabolic surgery as a treatment option for the escalating Obesity epidemic is effective and successful. There is uncertainty regarding the selection of obese patients for metabolic procedures, how to define a successful outcome and pre-operative predictors of success. Not all obese patients are candidates for metabolic surgery. Indeed, obese patients who are chosen for metabolic surgery are a unique cohort of patients, and the characteristics of this cohort need to be well identified. In these patients, there is a definite impact of obesity on quality of life (QOL). The magnitude of this impact on the various domains of Health Related (HR) QOL in this unique cohort of patients is unclear.

\section{Objective}

The aim of this study was to explore the influence of obesity on preoperative quality of life in patients awaiting bariatric surgery.

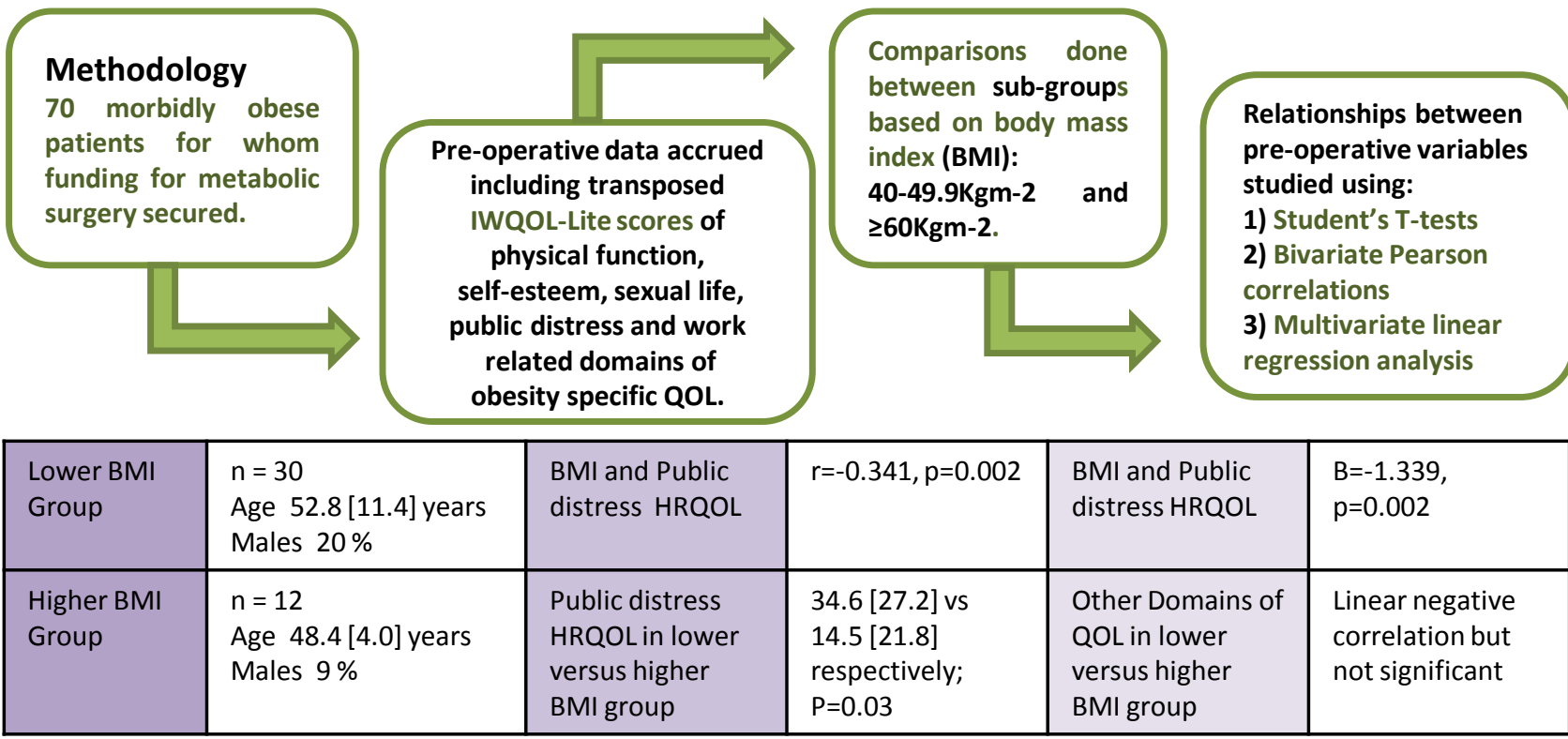

\section{Conclusion}

In the unique cohort of obese patients awaiting metabolic surgery, BMI appears to influence all domains of QOL in a negative linear fashion but is only significant for public distress HRQOL

\section{Take Home Points}

1) Measures of improvement in physical-psycho-sexual QOL are important considerations in the clinical assessment of morbidly obese patients when contemplating metabolic surgery

2) Pre-operative QOL may possibly predict other measures of metabolic surgical success, such as improvements in psycho-social functioning.

3) Improvements of QOL measures should feature in the definition of successful metabolic surgical outcomes in addition to weight loss

\section{References}

1) Forhan M, Vrkljan B, MacDermid J. A systematic review of the quality of psychometric evidence supporting the use of an obesity-specific quality of life measure for use with persons who have class III obesity. Obes Rev. 2010 Mar;11(3):222-8

2) Belanger SB, Wechsler FS, Nademin ME, Virden TB 3rd. Predicting outcome of gastric bypass surgery utilizing personality scale elevations, psychosocial factors, and diagnostic group membership. Obes Surg 2010 Oct;20(10):1361-71 